\title{
Clinical added-value of 18FDG PET in neuroendocrine-Merkel cell carcinoma
}

\author{
TARIK BELHOCINE ${ }^{1}$, GERALD E. PIERARD ${ }^{2}$, JANOS FRÜHLING ${ }^{1}$, GAËTAN LETESSON $^{3}$, STEPHANIE BOLLE ${ }^{4}$, \\ ROLAND HUSTINX ${ }^{3}$, JEAN-LOUIS DARGENT ${ }^{5}$, PATRICK FLAMEN ${ }^{1}$ and PIERRE RIGO ${ }^{6}$
}

\begin{abstract}
${ }^{1}$ Department of Nuclear Medicine, Jules Bordet Cancer Institute, Brussels; Departments of ${ }^{2}$ Dermatopathology, ${ }^{3}$ Nuclear Medicine, and ${ }^{4}$ Radiotherapy, University Hospital of Liège, Liège, Belgium; ${ }^{5}$ Department of Dermatology, Jules Bordet Cancer Institute, Brussels; ${ }^{6}$ Department of Nuclear Medicine, Hôpital Princesse Grace, Monte Carlo, Monaco
\end{abstract}

Received November 21, 2005; Accepted March 21, 2006

\begin{abstract}
Merkel cell carcinoma (MCC) is a rare and highly malignant skin cancer with neuroendocrine differentiation. We studied the potential value of ${ }^{18} \mathrm{FDG}$ PET in the management of MCC. Eleven patients with MCC were examined by ${ }^{18} \mathrm{FDG}$ PET and PET-CT for staging purpose $(n=4)$ or for detection of recurrence $(n=7)$. Qualitative and quantitative interpretation of PET studies was performed routinely. ${ }^{18} \mathrm{FDG}$ PET observations were compared to clinical and radiological findings. In 6 patients, PET findings were also compared to histology. In 7 patients, the ${ }^{18} \mathrm{FDG}$ tumor uptake was compared to the MCC proliferative activity expressed by the Ki-67 index. ${ }^{18} \mathrm{FDG}$ PET was contributive in $10 / 11 \mathrm{MCC}$ patients. In 7 patients, ${ }^{18} \mathrm{FDG}$ PET detected focal lesions or a disseminated stage of the disease including dermal, nodal and visceral metastases. In 3 patients, a normal ${ }^{18} \mathrm{FDG}$ PET confirmed complete remission of disease. Most MCC patients exhibited highly ${ }^{18}$ FDG-avid sites suggestive of increased glucose metabolism. This imaging pattern was related to a high proliferative activity (Ki-67 index $>50 \%$ ). In 1 patient with a weakly proliferative nodal MCC (Ki-67<10\%), a false negative result was yielded by metabolic imaging. In $4 / 11$ patients, ${ }^{18} \mathrm{FDG}$ PET revealed an unsuspected second neoplasm in addition to MCC. It is concluded that whole-body ${ }^{18} \mathrm{FDG}$ PET may be useful in the management of MCC patients. However, a normal ${ }^{18} \mathrm{FDG}$ PET aspect cannot rule out MCC with low proliferative activity.
\end{abstract}

\section{Introduction}

Merkel cell carcinoma (MCC) is thought to be issued from Merkel cells $(1,2)$. It is a highly aggressive skin cancer

Correspondence to: Professor Gérald E. Pierard, Department of Dermatopathology, CHU Sart Tilman, B-4000 Liege, Belgium

E-mail: gerald.pierard@ulg.ac.be

Key words: Merkel cell carcinoma, ${ }^{18}$ FDG PET, PET-CT, neuroendocrine tumor exhibiting neuroendocrine differentiation $(1,2)$. Although the neoplasm remains infrequent, its incidence is on the rise (3). MCC tends to predominantly invade the regional draining nodes. The $67 \%$ mortality of node-positive patients contrasts with $23 \%$ of patients without nodal involvement (4). At first presentation, MCC has often spread to distant sites including the liver, brain, skeleton, lungs and gastrointestinal tract $(5,6)$. The etiology of this malignancy is still unknown. Documented cases have reported MCC after radiation and immunosuppressive therapies, or in association with other cancers (7).

To date, no standardized procedure is defined for the management of MCC patients. Conventional imaging techniques, including ultrasonography (US), computed tomography $(\mathrm{CT})$, and magnetic resonance imaging (MRI), are commonly performed for pre-treatment staging as well as in post-treatment follow-up. The use of lymphatic mapping and sentinel lymphadenectomy (LM/SL) has been advocated for detecting MCC lymph node metastases $(8,9)$. New developments for efficient staging work-up aimed at detecting regional and distant MCC metastases are welcome owing to the inherent aggressiveness of the neoplasm. Such procedures are critical for selecting the appropriate means for local therapy (surgery and/or radiotherapy) and systemic radiochemotherapy (10).

The present study was undertaken to evaluate the usefulness of ${ }^{18} \mathrm{~F}$-fluorodeoxyglucose positron emission tomography $\left({ }^{18} \mathrm{FDG}\right.$ PET) in detecting MCC. This metabolic imaging technique uses radiolabelled glucose tracer as the marker of malignancy.

\section{Patients and methods}

Patients. Eleven patients ( 7 women and 4 men, mean age: 63.5 years) with proven MCC were examined by ${ }^{18}$ FDG PET. Owing to the rarity of the disease, we collected cases of MCC patients from two different institutions. Patient demographics are detailed in Table I. Overall, $15{ }^{18}$ FDG PET examinations were performed including 4 PET scans in pre-treatment staging (4 patients), and 11 PET scans (7 patients) during posttreatment follow-up.

${ }^{18}$ FDG PET imaging. The $11 \mathrm{MCC}$ patients were examined using dedicated PET devices. Eight PET assessments (6 patients) were performed on an Advance PET scanner (GEMS, 
Table I. Patient demographics.

\begin{tabular}{cccccc}
\hline Patients & Age (years) & Gender & Primary site & Primary therapy & Stage \\
\hline 1 & 67 & F & Left thigh & WLE + chemo-radiation & I \\
2 & 46 & F & Left foot & WLE + radiation & I \\
3 & 53 & F & Left knee & WLE + radiation & I \\
4 & 67 & F & Right buttock & WLE & I \\
5 & 60 & M & Abdomen & WLE + chemotherapy & III \\
6 & 70 & M & Left groin & WLE + radiation & I \\
7 & 57 & M & Left shoulder & WLE + chemo-radiation & II \\
8 & 63 & M & Intranodal & WLE + radiation & II \\
9 & 77 & F & Left buttock & WLE & I \\
10 & 75 & F & Right buttock & WLE & I \\
11 & 78 & F & Left calf & WLE & I \\
\hline
\end{tabular}

WLE, wide local excision.

Nxi, Milwaukee, USA) and four PET assessments (4 patients) were performed on NaI crystal-based PET scanners (UGM PENN PET $240 \mathrm{H}$ or C-PET). In addition, three PET examinations (3 patients) were performed on a PET-CT device (GEMS, Discovery LS, Milwaukee, USA). In all cases, emission data were corrected for attenuation by using either a radioactive source $\left({ }^{68} \mathrm{Ge}\right.$ or ${ }^{137} \mathrm{Cs}$ sources $)$ or a CT scan for transmission purposes. All patients were prepared according to a standard protocol routinely used in oncology ${ }^{18} \mathrm{FDG}$ PET. On average, the acquisition started $60 \mathrm{~min}$ after intravenous injection of glucose tracer. In the meantime, all subjects were kept at rest in a quiet environment. To improve the quality of images, some medicines were administered orally in order to reduce muscle contraction (10 $\mathrm{mg}$ diazepam) and bowel retention (10 mg mebeverine). Intravenous injection of $20 \mathrm{mg}$ furosemide was administered to minimize the tracer stasis into the urinary tract. In all cases, standard whole-body PET was performed to cover the body from the base of the skull to mid-thigh. In two patients with a suspected local recurrence, the field of view was extended to the lower extremities. The duration of the PET procedure ranged from 45 to $75 \mathrm{~min}$. Overall, the images were displayed using dedicated software in sagittal, transaxial and coronal slices for routine visual interpretation. To assess the glucose tracer intensity inside tumoral sites, semi-quantitative analysis of ${ }^{18} \mathrm{FDG}$ uptakes was performed on all abnormal sites including MCC metastatic lesions and other malignancies. Accordingly, standardized uptake value-body weight scores (SUV-BW = decay-corrected tissue activity divided by the injected activity per patient body weight) were calculated using a conventional computerized method. Regions of interest (ROIs) were drawn on all ${ }^{18}$ FDG-avid sites on the transaxial slices. Maximum SUV-BW values (SUV-BW max) were retained for each tumor site. As a rule, ${ }^{18} \mathrm{FDG}$-avid sites with SUV-BW scores $>3$ are suggestive of malignancy.

Confirmation of ${ }^{18}$ FDG PET findings. Fifteen PET examinations were performed in $11 \mathrm{MCC}$ patients. A positive PET scan was yielded in 7 patients (11 PET scans), and 4 patients (4 PET scans) had a negative PET scan. In all cases, ${ }^{18} \mathrm{FDG}$
PET findings were compared to the clinical follow-up and conventional imaging including CT/MRI and bone scan. In 6/7 patients with a positive PET scan (6 PET scans) histo- and immunohistochemistry were also performed ( 3 after surgery, 2 after biopsy, and 1 at autopsy). Three patients (3 PET scans) with negative PET findings were clinically and radiologically followed-up for 6, 20 and 24 months, respectively. In 1 patient (1 PET scan) with negative PET findings, LM/SL was performed during the week following the PET assessment and allowed the detection of regional nodal involvement.

PET correlation with the Ki-67 index. In order to correlate ${ }^{18} \mathrm{FDG}$ uptake patterns with tumor aggressiveness, the size of the MCC germinative pool was assessed by means of the Ki-67 index using the monoclonal antibody, MIB-1 (Dako ${ }^{\circledR}$, Glostrup, DK). The available MCC specimens (7/11 patients) corresponded to 4 primary tumors and 3 lymph node metastases. For the other 4 patients, the formalin-fixed, paraffin-embedded material was not sufficient for further analyses.

Statistical analysis. The diagnostic performance of ${ }^{18} \mathrm{FDG}$ PET for detecting MCC and any second neoplasm was assessed in terms of sensitivity and specificity. The assessment was considered as a true positive result (TP) when the PET findings were confirmed by histology or consistent followup. Conversely, the PET assessment was defined as a false positive result (FP) in the absence of objective confirmation for malignancy. The assessment was considered as a true negative result (TN) when the absence of tumor by PET was confirmed after a minimum 6-month follow-up. The detection of tumors by conventional imaging or sentinel node biopsy, which were missed by ${ }^{18}$ FDG PET, was interpreted as a false negative result $(\mathrm{FN})$.

\section{Results}

The clinical characteristics and growth patterns of MCC patients explored by ${ }^{18} \mathrm{FDG}$ PET and PET-CT are detailed in Table II. In this series, ${ }^{18}$ FDG PET was contributive in $10 / 11$ 
Table II. Clinical and growth patterns in MCC patients explored by ${ }^{18} \mathrm{FDG}$ PET.

\begin{tabular}{|c|c|c|c|c|c|c|}
\hline Patient & Indications & ${ }^{18}$ FDG PET patterns & 2nd neoplasms & SUV-BW max & $\begin{array}{l}\text { Ki-67 indexes/ } \\
\text { specimens }\end{array}$ & Correlation \\
\hline 1 & Staging & $\begin{array}{l}\text { Disseminated disease: skeleton (femurs, sacro- } \\
\text { iliac), right lung }\end{array}$ & NSCLC & Not available & Not available & $\begin{array}{l}\text { Histology +/ } \\
\mathrm{CT}+/ \mathrm{MRI}+\end{array}$ \\
\hline 2 & Follow-up & Disseminated disease: left lung, mediastinum & NSCLC & 7.70 & Not available & Histology $+/ \mathrm{CT}+$ \\
\hline 3 & Follow-up & Normal & & Not applicable & $\begin{array}{l}\text { 8-38\%: primary } \\
\text { tumor }\end{array}$ & $\begin{array}{l}\text { Follow-up -/ } \\
24 \text { months }\end{array}$ \\
\hline 4 & Staging & Normal & $\begin{array}{l}\text { NHL } \\
\text { Breast cancer }\end{array}$ & Not applicable & $\begin{array}{l}\text { 4-13\%: sentinel } \\
\text { lymph nodes }\end{array}$ & $\mathrm{LM} / \mathrm{SL}+$ \\
\hline 5 & Follow-up & $\begin{array}{l}\text { Disseminated disease: right lung, skeleton } \\
\text { (ribs, spine), hilar and mediastinal lymph nodes }\end{array}$ & NSCLC & $4.89-37.17$ & Not available & $\mathrm{CT}+$ /Bone scan + \\
\hline 6 & Staging & Normal & & Not applicable & $\begin{array}{l}10-15 \% \text { : primary } \\
\text { tumor }\end{array}$ & $\begin{array}{l}\text { Follow-up -/ } \\
20 \text { months }\end{array}$ \\
\hline 7 & Follow-up & $\begin{array}{l}\text { Disseminated disease: axillary lymph nodes, } \\
\text { pleura, rib, liver }\end{array}$ & & $3.75-12.59$ & $\begin{array}{l}\text { 50-75\%: axillary } \\
\text { lymph nodes }\end{array}$ & $\begin{array}{l}\text { Autopsy }+/ \mathrm{CT}+/ \\
\mathrm{MRI}+\end{array}$ \\
\hline \multirow[t]{2}{*}{8} & Follow-up & Focal disease: left inguinal node & & 3.13 & $\begin{array}{l}65-75 \% \text { : inguinal } \\
\text { lymph nodes }\end{array}$ & Histology + \\
\hline & Follow-up & Normal & & Not applicable & & $\begin{array}{l}\text { Follow-up -/ } \\
6 \text { months }\end{array}$ \\
\hline \multirow[t]{3}{*}{9} & Follow-up & Focal disease: left inguinal node & & 9.34 & $\begin{array}{l}45-50 \% \text { : primary } \\
\text { tumor }\end{array}$ & Histology $+/ C T+$ \\
\hline & Follow-up & Focal disease: iliac lymph node & & 10.77 & & Histology $+/ \mathrm{CT}+$ \\
\hline & Follow-up & Focal disease: mediastinal lymph node & & 10.89 & & $\mathrm{CT}+$ \\
\hline 10 & $\begin{array}{l}\text { Staging } \\
\text { Follow-up }\end{array}$ & $\begin{array}{l}\text { Focal disease: thymus } \\
\text { Disseminated disease: thymus, retroperitoneal } \\
\text { lymph nodes }\end{array}$ & Thymoma & $\begin{array}{l}7.96 \\
5.40-10.7\end{array}$ & Not available & $\begin{array}{l}\mathrm{CT}+ \\
\mathrm{CT}+\end{array}$ \\
\hline 11 & Follow-up & $\begin{array}{l}\text { Disseminated disease: dermal nodules, inguinal } \\
\text { and iliac lymph nodes, lungs, pleura }\end{array}$ & & $4.25-13.51$ & $\begin{array}{l}20-45 \% \text { : primary } \\
\text { tumor }\end{array}$ & $\mathrm{CT}+$ \\
\hline
\end{tabular}

NHL, non-Hodgkin's lymphoma; NSCLC, non-small cell lung cancer; SUV-BW max, standardized uptake value-body weight max (SUV-BW max >3 is suggestive of malignancy).

MCC patients (14/15 PET scans). In 11 PET assessments, metabolic imaging showed either multiple ${ }^{18}$ FDG-avid foci (6 PET scans) or a single intense focus (5 PET scans). In all of these cases, ${ }^{18}$ FDG PET findings were confirmed as MCC metastases or as other cancers associated to MCC. Correlations were obtained by histology or by other imaging modalities including CT, MRI and bone scan. In the remaining 4 PET assessments, metabolic imaging showed no ${ }^{18} \mathrm{FDG}$-avid abnormality. Among them, 3 PET findings were considered as TN results with no evidence of disease after a clinical and radiological follow-up of 6,20 and 24 months, respectively. A single PET scan led to a FN result in the case of nodal metastases. This patient had sentinel lymph node metastases larger than $1 \mathrm{~cm}$ with a relatively low proliferative activity (Ki-67 index: 4-13\% according to the microscopic field).

Analysis by sites showed that whole-body PET detected ${ }^{18}$ FDG-avid tumors on the entire body. All of these metabolically active tumor sites had SUV-BW scores $>3$, including dermal metastases surrounding the primary neoplasm, regional and distant nodal disease, as well as visceral localisations including lung, pleural, liver and bone metastases (Fig. 1). Most of the sampled MCC lesions for histology exhibited a moderate to high degree of proliferation with a Ki-67 index ranging from 10 to $75 \%$ (mean: $50 \%$ ). In 4/11 patients, metabolic imaging also revealed an unsuspected second neoplasm associated to MCC at primary staging (1 non-small cell lung cancer, and 1 thymoma), as well as during the follow-up ( 2 non-small cell lung cancers). Most metastases arising from MCC and the second neoplasm were detected by PET examination using routine qualitative and quantitative interpretation of images. In 3 patients, PET-CT allowed a more precise anatomic localisation of ${ }^{18} \mathrm{FDG}$-avid tumor sites, especially for detecting retroperitoneal and mediastinal lymph nodes, and for confirming pleural involvement. However, in one patient with multiple ${ }^{18} \mathrm{FDG}$-avid foci, metabolic imaging missed the brain metastases detected by MRI.

Overall, ${ }^{18}$ FDG PET exhibited a 92\% sensitivity (11 TP and $1 \mathrm{FN}$ ) and a $100 \%$ specificity ( $3 \mathrm{TN}$ and $0 \mathrm{FP}$ ) in the detection of MCC tumors and associated malignancies.

\section{Discussion}

$\mathrm{MC}$ is a highly malignant neoplasm that may represent the most aggressive skin cancer $(1,10)$. Owing to the rarity of the 
a

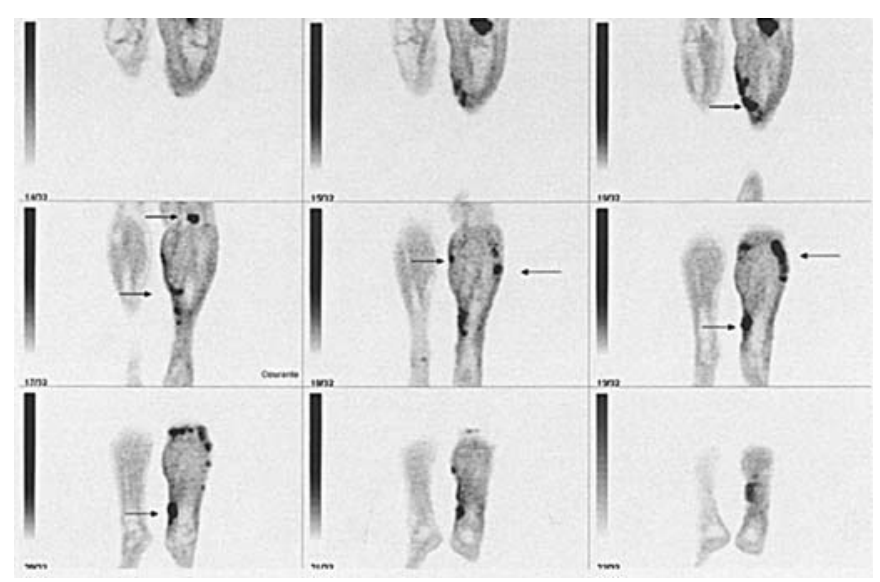

c b
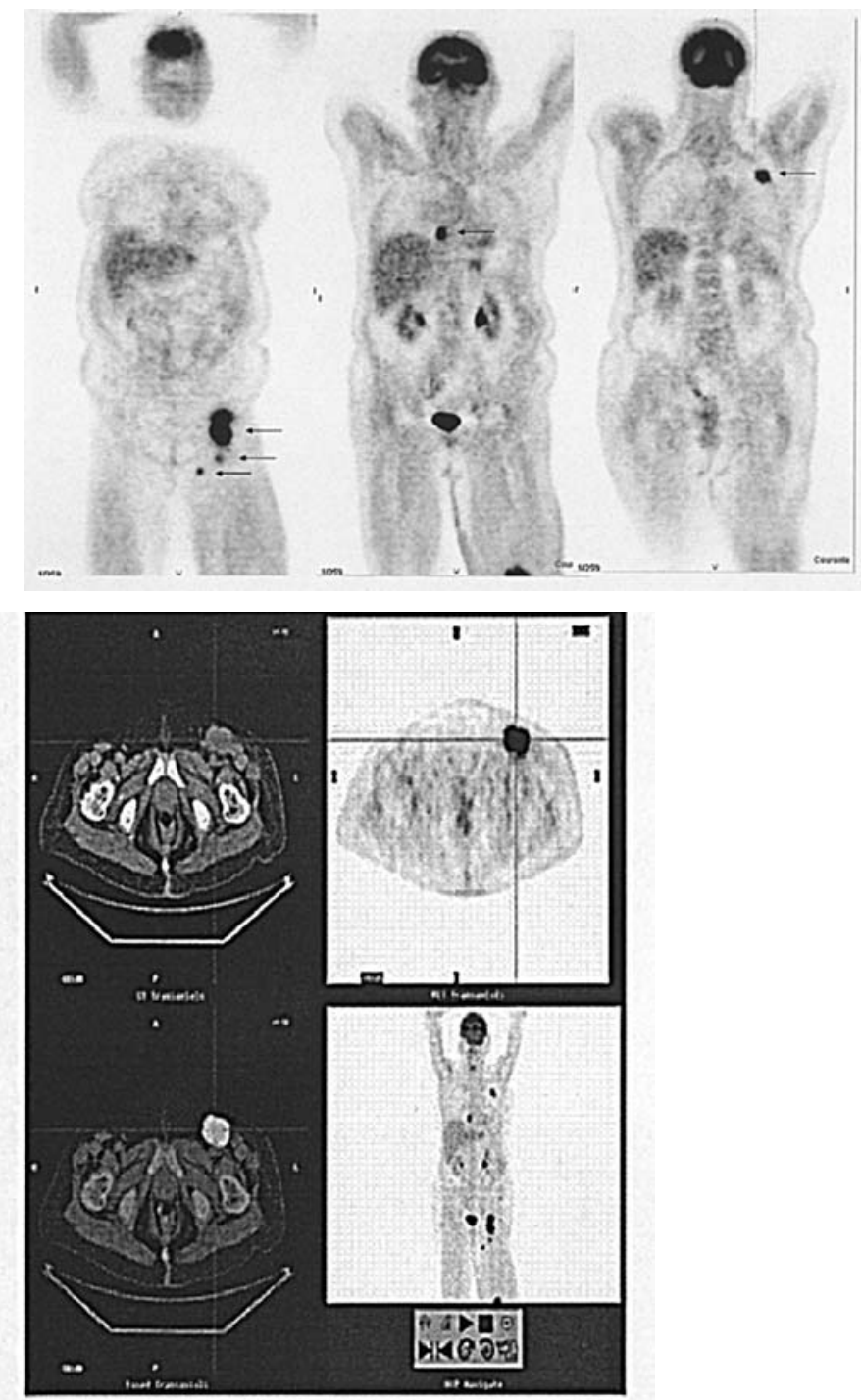
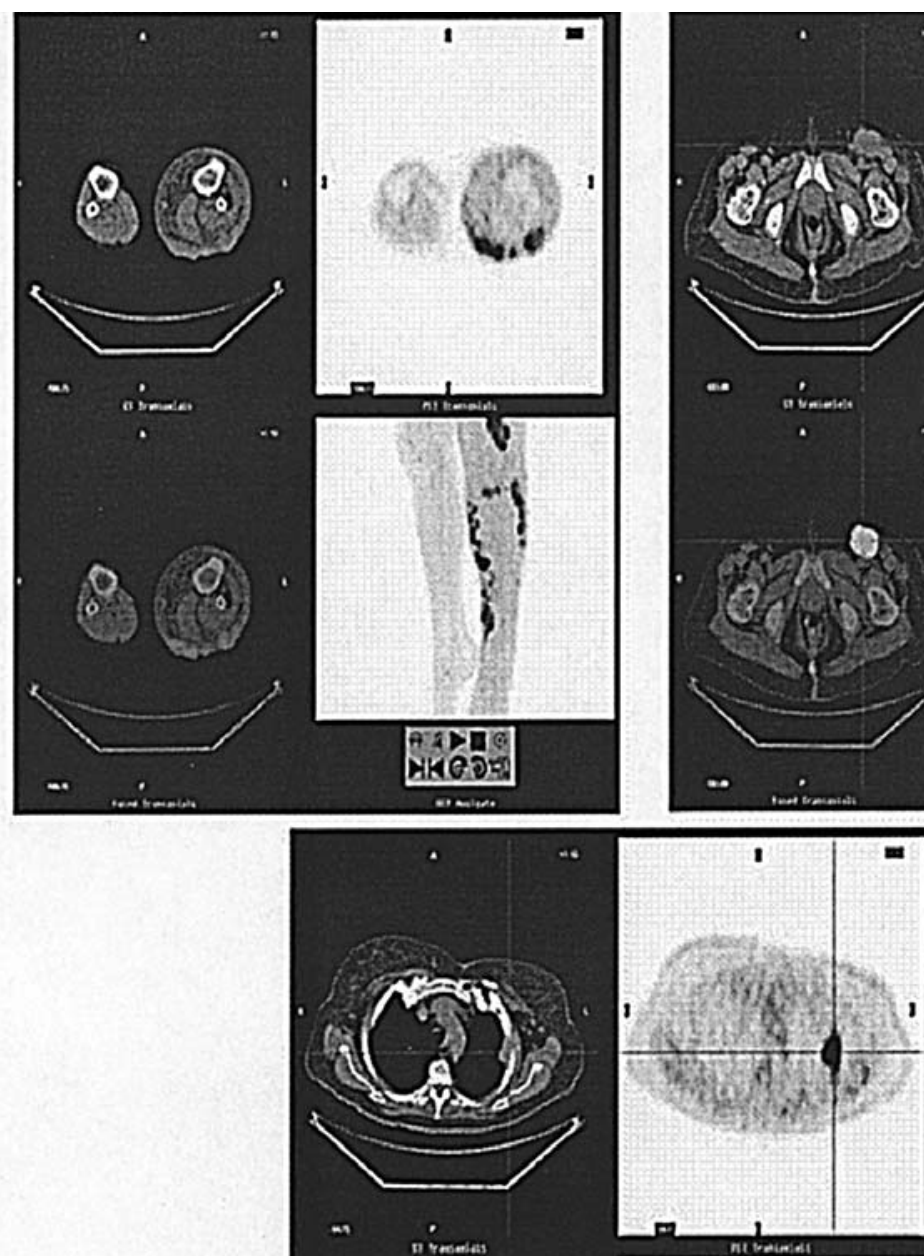

a niment

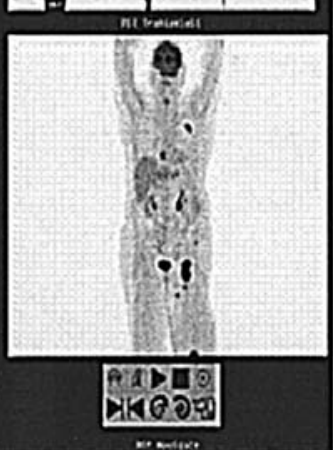

Figure 1. A 78-year-old woman with MCC of the left calf was explored for re-staging purposes. Whole-body ${ }^{18}$ FDG PET-CT revealed (arrows) dermolymphatic metastases at the level of the primary tumor (a) as well as regional lymph nodes and distant lung metastases (b). Combined PET-CT images allowed precise anatometabolic localization of the tumor sites (c). 
Table III. ${ }^{18}$ FDG PET and Merkel cell carcinoma: review of the literature.

\begin{tabular}{|c|c|c|c|c|}
\hline Authors & Year & No. of patients & Clinical indications & Comments \\
\hline Lampreave et al & 1998 & 1 & Staging-restaging & ${ }^{18}$ FDG $\mathrm{PET}>\mathrm{CT}$ \\
\hline Wong et al & 2000 & 1 & Staging & ${ }^{18}$ FDG PET $>$ SRS \\
\hline Nguyen et al & 2002 & 1 & Restaging & ${ }^{18} \mathrm{FDG}$ PET $>\mathrm{CT}$ \\
\hline Lin et al & 2004 & 1 & Staging-restaging & ${ }^{18} \mathrm{FDG} \mathrm{PET}>\mathrm{CT} / \mathrm{MRI}$ \\
\hline Scanga et al & 2004 & 2 & Staging-restaging & ${ }^{18} \mathrm{FDG} \mathrm{PET}>\mathrm{CT} / \mathrm{MRI}$ \\
\hline Min et al & 2005 & 2 & Staging-restaging & $\mathrm{PET}>\mathrm{CT}$ \\
\hline Belhocine et al & 2005 & 11 & Staging-restaging & ${ }^{18} \mathrm{FDG}$ PET $(\mathrm{PET} / \mathrm{CT})>\mathrm{CT}$ \\
\hline Grewal et al & 2005 & 23 & Staging-restaging & ${ }^{18}$ FDG PET alone \\
\hline \multirow[t]{3}{*}{ Talbot et al } & 2005 & 3 & Staging-restaging & ${ }^{18}$ FDG PET>SRS \\
\hline & & & & Tumor uptake: ${ }^{18} \mathrm{FDG}>{ }^{18} \mathrm{FDOPA}$ \\
\hline & & & & Specificity: ${ }^{18} \mathrm{FDOPA}>{ }^{18} \mathrm{FDG}$ \\
\hline Golan et al & 2005 & 1 & Restaging & ${ }^{18} \mathrm{FDG}$ PET $>\mathrm{CT}$ \\
\hline
\end{tabular}

${ }^{18} \mathrm{FDG},{ }^{18} \mathrm{~F}$-fluoro-2-deoxy-D-glucose; ${ }^{18} \mathrm{FDOPA},{ }^{18} \mathrm{~F}-$ fluoro-L-dihydroxyphenylalanine; SRS, somatostatin receptors scintigraphy; PET, positron emission tomography; CT, computed tomography; CI, conventional imaging.

disease, however, no standardized approach is currently defined to optimally manage MCC patients, both in the pre-treatment set-up and in the post-treatment follow-up (11). In recent years, functional imaging methods using LM/SL and somatostatin receptor scintigraphy (SRS) have been shown to efficiently complement morphological imaging $(8,11,12)$. This holds particularly true in stage I and II MCC patients with local and regional involvement, respectively (11). So far, LM/SL cannot assess the full extent of the disease, especially in stage III patients with disseminated disease to nodal and visceral sites. Similarly, SRS is often of limited value for detecting metastases in organs such as liver, kidneys and spleen showing a physiological uptake of radiolabelled octreotide (12).

Because the ${ }^{18}$ FDG tracer is avidly taken up in highly aggressive malignancies including cutaneous melanoma, we investigated the potential benefit of metabolic imaging to detect ${ }^{18} \mathrm{FDG}$-avid sites from MCC. Additionally, in many types of cancer, whole-body ${ }^{18}$ FDG PET appears to be more sensitive and more specific than conventional imaging including US, CT and MRI (13). Until now, only a few case reports have suggested the clinical feasibility of ${ }^{18}$ FDG PET in MCC patients [(14-20); Scanga D, et al, J Nucl Med 46 (Suppl 2): abs. 137, 2005]. Although limited, these findings highlighted the addedvalue of metabolic imaging for detecting metastases from MCC as well as for localizing local and distant recurrences, which were missed by conventional imaging including CT and SRS (Table III).

In the present study on MCC cases, all ${ }^{18} \mathrm{FDG}$ PET findings were confirmed histologically or by clinical and radiological follow-up. Regardless to PET model, our findings indicate that MCC sites exhibit increased ${ }^{18} \mathrm{FDG}$ uptake according to routine qualitative and quantitative interpretation. In an attempt to correlate glucose metabolism with MCC biology, we assessed the Ki-67 index as a marker of cycling cells, bearing in mind that neuroendocrine tumors (NETs) with a rapid growth or aggressive behavior were found to be highly ${ }^{18} \mathrm{FDG}$-avid, while slow-growing NETs usually showed no or low FDG uptake (21-23). In the present series, all MCC specimens expressed a large germinative compartment, thereby confirming the importance of cell proliferation as a key factor in the biologic behavior of MCC (24). Nonetheless, the heterogeneity in the MCC tumor samples prevented any firm conclusion as to the biological significance of ${ }^{18} \mathrm{FDG}$ uptake in primary tumors and nodal metastases.

In the management of MCC patients, ${ }^{18} \mathrm{FDG}$ PET may offer several advantages in pre-treatment staging as well as in post-treatment follow-up. A single, whole-body PET procedure helps to avoid repeated and time-consuming conventional imaging assessments. In addition, metabolic characterization may precede some imaging expression. ${ }^{18} \mathrm{FDG}$ PET may also be useful to reliably rule out recurrence from MCC, especially when conventional work-up cannot distinguish between posttreatment changes and tumor recurrence. The strength of metabolic imaging relies on its capability to detect malignancy sites over the entire body, including lymphatic lesions (dermal and nodal sites) or haematogenous metastases. As such, whole-body ${ }^{18}$ FDG PET may significantly impact the treatment options in terms of loco-regional disease versus disseminated disease. In the present series, most of the patients had standard whole-body PET from the base of the skull to mid-thigh. Some of them had an extended field of view to cover the lower extremities and the brain. Owing to the aggressiveness of MCC, a true total body scan from the top of the head to the tip of the toes may be warranted, especially with faster PET-CT devices (20). So far, metabolic imaging remains suboptimal for the detection of brain metastases due to the high cerebral background (25). Therefore, brain MRI should complement standard whole-body ${ }^{18}$ FDG PET as routinely performed in malignant melanoma. The present findings also highlight the added-value of combined PET-CT device for better anatomic localization of ${ }^{18} \mathrm{FDG}$-avid tumor sites. This may be particularly relevant for a precisely targeted radiation 
treatment. Despite the heterogeneity of the study group, ${ }^{18} \mathrm{FDG}$ PET was able to detect other cancers in 4/11 MCC patients. Second neoplasms are frequently associated to primary MCC, including skin carcinomas and non-cutaneous solid tumors as well as haematological diseases $(26,27)$. This provides a strong argument for the performance of whole-body ${ }^{18} \mathrm{FDG}$ PET in the staging and re-staging of MCC.

Recently, the feasibility of ${ }^{18} \mathrm{~F}-\mathrm{FDOPA}$ was reported in three patients with proven MCC-neuroendocrine tumors (28). MCC tumor sites exhibited a more intense uptake with ${ }^{18} \mathrm{FDG}$ compared to ${ }^{18} \mathrm{~F}$-FDOPA. In this case report, ${ }^{18} \mathrm{~F}$-FDOPA PET did not show more extra-cranial metastases from MCC than ${ }^{18}$ FDG PET. So far, ${ }^{18}$ F-FDOPA may be of particular interest for detection of brain metastases that are often missed with ${ }^{18} \mathrm{FDG}$ PET. Additionally, the high specificity of ${ }^{18} \mathrm{~F}-\mathrm{FDOPA}$ for neuroendocrine tumors may help to rule out FP results and equivocal findings obtained with ${ }^{18} \mathrm{~F}-\mathrm{FDG}$ and SRS (28). Although our study group included only 11 MCC patients who underwent $15{ }^{18} \mathrm{FDG}$ PET evaluations, this low number is in line with most published series owing to the rarity of the disease (29). So far, the retrospective nature of the study limits the possibility of more sophisticated analysis in terms of patient survival and treatment impact. Further studies appear warranted to confirm the promising findings, and to address other keyissues in the management of MCC patients.

Based on the present findings, the use of whole-body ${ }^{18} \mathrm{FDG}$ imaging may be clinically contributive in the management of MCC patients. However, a normal ${ }^{18}$ FDG PET distribution cannot exclude the possibility of MCC with a low proliferative activity. Prospective multicenter studies will help collect more data to refine the role of ${ }^{18} \mathrm{FDG}$ PET along with LM/SL and ${ }^{18} \mathrm{~F}-\mathrm{DOPA}$ PET in various stages of MCC.

\section{References}

1. Toker C: Trabecular carcinoma of the skin. Arch Dermatol 105: 107-110, 1972.

2. Haag ML, Glass LF and Fenske NA: Merkel cell carcinoma diagnosis and treatment. Dermatol Surg 21: 669-683, 1995.

3. Hodgson NS: Merkel cell carcinoma: changing incidence trends. J Surg Oncol 89: 1-4, 2004.

4. Yiengpruksawan A, Coit DG, Thaler HT, Urmacher C and Knapper WK: Merkel cell carcinoma. Prognosis and management. Arch Surg 126: 1514-1519, 1991.

5. Hitchcock CL, Bland KI, Laney RG III, Franzini D, Harris B and Copeland EM III: Neuroendocrine (Merkel cell) carcinoma of the skin: its natural history, diagnosis and treatment. Ann Surg 207: 669-683, 1988.

6. Mott RT, Smoller BR and Morgan MB: Merkel cell carcinoma: a clinicopathologic study with prognostic implications. J Cutan Pathol 31: 217-223, 2004.

7. Shaw JHG and Rumball E: Merkell cell tumor: clinical behavior and treatment. Br J Surg 78: 138-142, 1991.

8. Wasserberg N, Schachter J, Fenig E, Feinmesser M and Gutman H: Applicability of the sentinel node technique to Merkel cell carcinoma. Dermatol Surg 26: 134-138, 2000.

9. Medina-Franco H, Urist MM, Fiveash J, Heslin MJ, Bland KI and Beenken SW: Multimodality treatment of Merkel cell carcinoma: case series and literature review of 1024 cases. Ann Surg Oncol 8: 204-208, 2001.

10. Poulsen M: Merkel-cell carcinoma of the skin. Lancet Oncol 5: 593-599, 2004.
11. Nguyen B and McCullough AE: Imaging of Merkel cell carcinoma. Radiographics 22: 367-376, 2002.

12. Kwekkeboom DJ, Hoff AM, Lamberts SW, Oei HY and Krenning EP: Somatostatin analogue scintigraphy: a simple and sensitive method for the in vivo visualization of Merkel cell tumors and their metastases. Arch Dermatol 128: 818-821, 1992.

13. Delbeke D: Oncological applications of FDG PET imaging: brain tumors, colorectal cancer, lymphoma and melanoma. J Nucl Med 40: 591-603, 1999.

14. Lampreave JL, Benard F, Alavi A, Jimenez-Hoyuela J and Fraker D: PET evaluation of therapeutic limb perfusion in Merkel's cell carcinoma. J Nucl Med 39: 2087-2090, 1998.

15. Wong CO, Pham AN and Dworkin HJ: F-18 FDG accumulation in an octreotide negative Merkel cell tumor. Clin Positron Imaging 3: 71, 2000.

16. Nguyen BD: Positron emission tomographic imaging of Merkel cell carcinoma. Clin Nucl Med 27: 922-923, 2002.

17. Lin O, Thomas A, Singh A and Greenspan B: Complementary role of positron emission tomography in Merkel cell carcinoma. South Med J 97: 1110-1112, 2004.

18. Scanga DR, Martin WH and Delbeke D: Value of FDG PET imaging in the management of patients with thyroid, neuroendocrine and neural crest tumors. Clin Nucl Med 29: 86-90, 2004.

19. Yao M, Smith RB, Hoffman HT, Funk GF, Graham MM and Buatti JM: Merkel cell carcinoma: two case reports focusing on the role of fluorodeoxyglucose positron emission tomography imaging in staging and surveillance. Am J Clin Oncol 28: 205-210, 2005.

20. Golan H, Volkov O, Linchinsky O and Melloul M: FDG-PET imaging in Merkel cell carcinoma - value of head-to-toe scan. Nucl Med Rev Cent East Eur 8: 135-136, 2005.

21. Pasquali C, Rubello D, Sperti C, Gasparoni P, Liessi G, Chierichetti F, Ferlin G and Pedrazzoli S: Neuroendocrine tumor imaging: can $18 \mathrm{~F}$-fluorodeoxyglucose emission tomography detect tumors with poor prognosis and aggressive behavior? World J Surg 22: 588-592, 1998.

22. Adams S, Baum RP, Hertel A, Schumm-Drager PM, Usadel KH and Hor G: Metabolic (PET) and receptor (SPET) imaging of well- and less well-differentiated tumors: comparison with the expression of the Ki-67 antigen. Nucl Med Commun 19: 641-647, 1998.

23. Belhocine T, Foidart J, Rigo P, Najjar F, Thiry A, Quatresooz P and Hustinx R: FDG-PET and somatostatin receptor scintigraphy for diagnosing and staging carcinoid tumors: correlations with the pathological indexes P53 and Ki-67. Nucl Med Commun 23: 727-734, 2002.

24. Skelton HG, Smith KJ, Hitchcock CL, McCarthy WF, Lupton GP and Graham JH: Merkel cell carcinoma: analysis of clinical, histologic and immunohistologic features of 132 cases with relation to survival. J Am Acad Dermatol 37: 734-739, 1997.

25. Larcos G and Maisey MN: FDG-PET screening for cerebral metastases in patients with suspected malignancy. Nucl Med Commun 17: 197-198, 1996.

26. Brenner B, Sulkes A, Rakowsky E, Feinmesser M, Yukelson A, Bar-Haim E, Katz A, Idelevich E, Neuman A, Barhana M and Fenig E: Second neoplasms in patients with Merkel cell carcinoma. Cancer 91: 1358-1362, 2001.

27. Gooptu C, Woolons A, Ross J, Price M, Wojnarowska F, Morris PJ, Wall S and Bunker CB: Merkel cell carcinoma arising after therapeutic immunosuppression. Br J Dermatol 137: 637-641, 1997.

28. Talbot JN, Kerrou K, Missoum F, Grahek D, Aide N, Lumbroso J and Montravers F: 6-F-18Fluoro-L-DOPA Positron emission tomography in the imaging of merkel cell carcinoma: preliminary report of three cases with 2-deoxy-2-f-18fluoro-d-glucose positron emission tomography or pentetreotide-111 inspect data. Mol Imaging Biol 5: 1-5, 2005.

29. Allen PJ, Bowne WB, Jaques DP, Brennan MF, Busam K and Coit DG: Merkel cell carcinoma: prognosis and treatment of patients from a single institution. J Clin Oncol 23: 2300-2309, 2005. 